\title{
Parenting Profiles versus Parenting Factors and Adolescents' Psychological Disorders
}

\author{
Marwan Dwairy ${ }^{1}$, Mona Fayad ${ }^{2} \&$ Naima Benyaqoub ${ }^{3}$ \\ ${ }^{1}$ Oranim Academic College, Tivon, Israel \\ ${ }^{2}$ Lebanese University, Beirut, Lebanon \\ ${ }^{3}$ University of Algeria, Algeria, Algeria \\ Correspondence: Marwan Dwairy, POBox 14710 Nazerat Ellit 17000, Israel. Tel: 972-054-633-4515. E-mail: \\ psy@marwandwairy.com
}

Received: February 8, 2013

Accepted: April 17, $2013 \quad$ Online Published: September 23, 2013

doi:10.5539/jedp.v3n2p1

URL: http://dx.doi.org/10.5539/jedp.v3n2p1

\begin{abstract}
The association between parenting and child's psychological states has been studied mainly according to Baumrind's model of authoritarian, authoritative, and permissive parenting styles or according to Rohner's acceptance-rejection theory. This study, in contrast, rests on the assumption that since parenting is a complex and dynamic process, it is better studied in terms of parenting profiles comprising several factors than via one or two parenting factors. We administered a questionnaire measuring seven parenting factors that cover various styles of acceptance and control to 975 male and female adolescents together with a scale of psychological states. Our results show that the associations between a parenting factor and psychological states depend on the presence or absence of other parenting factors, thereby justifying the use of parenting profiles rather than parenting factors. The psychological states were associated with the style of control and the parenting profile rather than with the level of control. Two paternal and three maternal parenting profiles were detected, each associated with different levels of psychological states. The profile characterized by high acceptance, rational parenting, and loving-control parenting, and by low compassion evoking, love withdrawal, inconsistent parenting, and authoritarian parenting was associated with better psychological states. The data were analyzed according to parents' and adolescents' sex and internalized and externalized psychological states. To learn more about parental profiles and psychological states, further research in different cultures is needed.
\end{abstract}

Keywords: parenting, control, authoritarian, acceptance, inconsistency, psychological states

\section{Introduction}

Most psychological theorists devote special attention to parent-child relations, especially in the first stages of development. Copious research on parenting seeks to identify central parental factors that are associated with children's psychological states and adjustment. In his psychosexual theory, Freud (1923/1962) claimed that both excessive satisfaction and dissatisfaction may cause a fixation and impair the child's psychological development. Object-relations theorists propose the goodenough mother as a golden path to healthy psychological development (Winnicott, 1956). Since then, many parental factors have been studied and associated with children's psychological adjustment. Baumrind (1966, 1991, 2005) suggests two orthogonal dimensions, high-low warmth and high-low control, and Schaefer (1965) suggests a similar pair (warmth-hostility and detachment-involvement). Rohner $(1986,1999)$ focuses on the dimension of parental acceptance-rejection in addition to parental control. The literature on these factors maintains that authoritarian and permissive (Baumrind), hostile and detached (Schaefer), and rejecting parenting (Rohner) have a negative impact on children's psychological adjustment. Whatever the parenting style, the primary author suggests inconsistency and incoherent parenting as another important factor associated with children's psychological disorders (Dwairy, 2007; Dwairy, Achoui, Abouserie, \&Farah, 2006).

The following introduction reviews the literature on Baumrind's and Rohner's parenting factors and the relationship between them and children's psychological disorders and provides initial empirical indications about the importance of inconsistency in parenting. 


\subsection{Baumrind's Parenting Style}

Baumrind's $(1966,1991)$ two-dimensional parenting factors (warmth and control) yield three major parenting styles: authoritarian, permissive, and authoritative. Authoritarian parents emphasize control and obedience, enforce discipline via punishment, and expect children to obey their orders without arguing (Baumrind, 1966, 1991, 2005; Reitman, Rhode, Hupp,\& Altobello, 2002). Permissive parents, in turn, allow children to make their own decisions and regulate their own behavior with minimal control. The authoritative parenting style lies somewhere between the authoritarian and the permissive. Authoritative parents enforce limits in various ways such as reasoning, verbal give-and-take, clear-cut instructions, and positive reinforcement. Authoritative parenting has been associated with better psychological adjustment of children (Baumrind, 1991, 2005; Steinberg, et al., 1991, 1992a, 1992b). Children of authoritative parents have high self-esteem and tend to be self-reliant, self-controlled, secure, popular, and inquisitive (Buri, Louiselle, Misukanis, \&Mueller, 1988; Wenar, 1994). (For a review of parental styles history, see Maccoby and Martin, 1983)

Readers of parenting literature encounter various overlapping and ill-defined concepts in reference to authoritarianism, such as controlling, strict, domineering, coercive, restrictive, regimenting, intrusive, interfering, demanding, and assertive of power. At the other end, they may find terms such as permissive, granting autonomy, indulgent, egalitarian, democratic, and laissez-faire (Rohner, \& Khaleque, 2003, 2005).

\subsection{Rohner's Acceptance-Rejection and Control Theory}

Rohner's parental acceptance-rejection theory arrays parenting styles on a continuum from acceptance (warm and affectionate) to rejection (cold, hostile, and indifferent) based on the extent of parental warmth toward children (Rohner, 1999, Rohner, Khaleque, \& Cournoyer, 2005). Perceived rejection is a major parental factor that is associated with several personality dispositions. Adolescents' reports of higher parental rejection explain $27 \%-46 \%$ of variance in their reports about psychological adjustment (Kim, Cain, \& McCubbin, 2006).

Rohner's theory also examines parental control on a range from permissiveness to strictness (Rohner et al.,2005). The relationship between parental control and children's psychological adjustment depends on the type of control: Control that inhibits psychological development is associated with depression, whereas behavioral control that regulates the child's behavior is associated with fewer conduct problems (Barber, Olsen, \& Shagle, 1994) and better academic achievement (Lamborn, Mounts, Steinberg, \& Dornbusch, 1991). Many studies had shown cross-gender differences in parenting practices and in the association between parenting (control and rejection) and children's psychological states (Dwairy, 2010; Dwairy, Achoui, 2010; Rohner, personal communication, August 13, 2010; Tulviste \& Rohner, 2010).

Both Rohner and Baumrind recognize the importance of warmth (Baumrind) or acceptance (Rohner) and the authoritarian (Baumrind) or controlling (Rohner) parental dimension. In fact, studies on parenting and children's psychological disorders focus on two factors: rejection and control. Despite our awareness of the significant influence of parenting on children's mental health, we should also realize that parenting is only one of many sociocultural and biological factors that affect children's mental health. In a meta-analysis study, parenting accounted for $8 \%$ of variance in child depression (McLeod, Weisz, \&Wood, 2007), less than $4 \%$ of variance in child anxiety (McLeod, Wood, \& Weisz, 2007), and less than 6\% of variance in externalizing problems (Rothbaum, \& Weisz, 1994). Parental rejection is more strongly related than parental control to depression; parental control is more related than parental rejection to anxiety (McLeod, Wood, \& Weisz, 2007).

\subsection{Dwairy's Inconsistency Hypothesis}

Unlike the negative effect of authoritarian parenting on Western adolescents, a regional study in eight Arab countries found no relation between authoritarian parenting and adolescents' psychological disorders (Dwairy, et al., 2006; Dwairy \& Menshar, 2006). Given these findings, the primary author attributes the negative effect of authoritarian parenting in the West to inconsistency between such parenting and the Western liberal culture. Conversely, Dwairy et al. (2006) found a connection between an inconsistent pattern of parenting that combines authoritarian and permissive modes with psychological disorders among Arab adolescents.

Although inconsistency in a child's social environment is frequently mentioned as one of the factors that may confuse the child and impair h/her learning and socialization processes (Wenar, 1994), it has not yet received the attention it deserves. Hersov (1960) points out that inconsistency between maternal and paternal parenting styles may amplify separation anxiety and school phobia; Dadds (1995) reports an association between inconsistent parenting and conduct disorders; and Patterson's coercion model (1982) links inconsistent parenting with conduct disorders.

To examine the effect of the inconsistency factor in parenting, Dwairy (2007) developed a scale for inconsistent 
parenting and conducted preliminary research to validate the scale and investigate the association between inconsistent parenting and adolescents' psychological disorders. The results found a connection between inconsistency measures and psychological disorders and no connection between authoritarian parenting measures and such disorders. Interestingly, Dwairy (2007) found no interaction between the effect of inconsistency and authoritarian parenting, suggesting that inconsistency has its own independent association with psychological disorders, irrespective of authoritarian parenting. In conclusion, the primary author suggests that in addition to parental rejection and control, parental inconsistency should be dealt with as an important parental factor that influences the psychological adjustment of children.

\subsection{Toward Multi-Factorial Studies on Parenting}

Thus far, research on parenting and children's psychological adjustment has typically been uni-factorial, testing one parenting factor at a time. This reductionism underestimates the interaction effect and the overlap that exists between different parenting factors (Soenens, 2007) and mistakenly treats each factor as an independent one. Due to this approach, the association found between certain parental factors and children's mental health is inconsistent and, at times, even contradictory. In our multi-factorial study, based on a systemic research approach (Dwairy, 2006), we assume that the association between specific parenting factors and children's mental health varies when it is tested in conjunction with, or without, other parenting factors. For instance, the association between parental rejection and children's mental health will depend on the presence or absence of one or more additional genetic, parental, familial, school, social, and cultural factors. (For more about the flaws of reductionism, see Dwairy, November 2006). In a systemic study of parenting, Dwairy (2009) showed that in a reductionist analysis that treats each factor separately, most parental factors have significant associations with adolescents' psychological disorders and, taken together, explain 37.2\% of adolescents' disorders. Most of these associations were diminished or modified in a systemic analysis that bundled all the factors together in one regression; in this case the same factors were found, collectively, to explain only $13.5 \%$ of the variance in psychological disorders. These findings indicate that reductionist analyses may yield illusionary associations and that mixed results are an inevitable if not an inherent byproduct of reductionist research.

Furthermore, since parenting is obviously a complex continuing and dynamic process, studying such a complex phenomenon via one or two parenting factors may be too simplistic and may omit many parenting practices that occur in the multi-factorial interactions that characterize parenting. Uni- or bi-factorial models of parenting, such as those based on the authoritarian-permissive axis or the acceptance-rejection scale, overlook several common parental practices and do not pinpoint variety in control practices, such as evoking compassion and guilt among children, control in the name of love and the child's welfare, or withdrawal of love and communication when the child misbehaves. These diverse practices may be considered different ways of control or rejection even though they are qualitatively different and may be associated with different children's outcomes. To address this, the present article attempts to combine seven parenting factors in one study. By capturing a variety of control practices, these factors may lead to the identification of parenting profiles of control and the study of their associations with children's psychological states.

Our research questions are:

1. What are the most common parental practices of fathers and mothers?

2. Can we identify different parental profiles of fathers and mothers?

3. How parenting factors and parenting profiles are associated with children's psychological disorders?

4. Are there cross-gender differences in parenting and in their associations with children's psychological disorders?

5. Is parenting associated differently with externalized or internalized psychological disorders?

\section{Method}

\subsection{Sample}

Although we did not deal with cultural issues at this initial stage of our research, we decided for reasons of convenience to start with an Arab sample in the belief that this choice is as legitimate as a decision by a Western researcher to begin with a Western sample. Our research was conducted on 975 Arab adolescents: 304 Palestinians, 205 Algerians, and 466 Lebanese aged 15-16, 51.9\% males and 48.1\% females. The administration was conducted at classrooms and lasted for about 40 minutes.

About $52.3 \%$ of fathers and $58.2 \%$ of mothers did not finish high school, $17.7 \%$ of fathers and $16.7 \%$ of mothers finished only high school (twelve years of education), and $30.0 \%$ of fathers and $25.1 \%$ of mothers had more 
advanced schooling: a diploma, a baccalaureate degree, or a higher degree. When the adolescents were asked to rate their family's economic level as compared with their peers' families, $65.2 \%$ characterized it as average, $26.5 \%$ above average, and only $8.3 \%$ below average.

\subsection{Instruments}

\section{Dwairy's Parenting Profile Scale (DPPS):}

Development of DPPS: This scale measures seven parenting factors that the primary author (Dwairy) identified and defined on the basis of his clinical experience with parents and children and on the literature on parenting styles and factors. In addition to the well-known factors of acceptance-rejection and authoritarian-permissive, the author identified five more styles of control: rational parenting, loving control, compassion evoking, love withdrawal, and inconsistent parenting.

Acceptance (Acp), e.g., "My mother usually accepts my conduct with love, without criticism." This factor resembles Rohner's acceptance factor.

Rational parenting (RtioP): Parents use logic behavioral techniques for control, e.g., "My father explains what he expects of me and uses logic to convince me." This factor may resemble Baumrind's authoritative parenting.

Loving control ( $\mathrm{LvCn})$ : Parents control and punish their children in the name of love and the child's welfare, e.g., "When my father punishes me, I know he is doing it for my own good."

Compassion evoking (CmEv): Parents evoke compassion and guilt in their children, e.g., "My mother often tells me how much she and the family are suffering because of me."

Love withdrawal (LvWd): Parents retreat from relations with their child, display dissatisfaction, and put on an angry face, e.g., "When I behave in a way my mother doesn't like, she ignores me and stops treating me kindly."

Inconsistent parenting (IncP): where the child cannot predict h/her parents' response, e.g., "My father's responses to my behavior are unpredictable and inconsistent."

Authoritarian parenting (AthP), e.g., "My father forces me to do what he wants me to do.'”This factor resembles Baumrind's authoritarian parenting.

For each factor, fifteen items were termed. To validate the scale, the seven factors were discussed and defined with three psychologists. Afterwards, the105 items were presented to them so that each could be related to one of the seven factors. Basing ourselves on this process, we chose ten items for each factor that on which the psychologists fully agreed. Then we formulated a scale that measures seven paternal and seven maternal parental factors composed of 140 items. For each factor, the subjects were asked to rate ten items for their truthfulness at four grades: $0=$ very low, $1=$ low, $2=$ much, and $3=$ very much.

We performed two principal factor analyses on the seventy items of the father and of the mother with a varimax rotation, a priori seven factors, and a .20 loading criterion. All ten items for each factor were loaded high in the same factor. Some items were loaded, although low, in another factor or other factors. The seven factors together explained $51.8 \%$ and $54.3 \%$ of the father and mother variance, respectively. Cronbach's alpha coefficients were .82 and .85 for fathers and mothers, respectively. An abridged version of the scale was formulated on the basis of the five highly loaded items for each factor and two additional principal factor analyses were conducted on the thirty-five items of father and mother with a varimax rotation, a priori seven factors, and a .20 loading criterion. All five items for each factor were loaded high in the same factor. The seven factors together explained $59.7 \%$ and $62.9 \%$ of the father and mother variance, respectively (Table 1 ).

Table 1. Factor analyses of DPPS and Cronbach's Alpha Coefficients of fathers and mothers

\begin{tabular}{|c|c|c|c|c|c|c|c|c|c|c|c|c|c|c|}
\hline & \multicolumn{7}{|c|}{ Fathers' factors } & \multicolumn{7}{|c|}{ Mothers' factors } \\
\hline & 1 & 2 & 3 & 4 & 5 & 6 & 7 & 1 & 2 & 3 & 4 & 5 & 6 & 7 \\
\hline Acp3 & & & & & & .67 & & & & & & & & .64 \\
\hline Acp5 & -.22 & & & & .28 & .59 & & .22 & & & & .21 & & .61 \\
\hline Acp6 & & & & & & .73 & & & & & & & -.21 & .75 \\
\hline Acp8 & & -.20 & & & .26 & .61 & & .22 & & & & .25 & & .60 \\
\hline
\end{tabular}




\begin{tabular}{|c|c|c|c|c|c|c|c|c|c|c|c|c|c|c|}
\hline Acp9 & & & & & & .74 & & & & & & & & .80 \\
\hline Rtio1 & & & & & .69 & & & & & & & .71 & & \\
\hline Rtio2 & & & .22 & & .69 & & & & & & & .74 & & \\
\hline Rtio8 & & & & & .67 & & & & & & & .70 & & \\
\hline Rtio9 & & & & & .78 & & & & & & & .79 & & \\
\hline Rtio10 & & & & & .71 & & & & & & & .72 & & \\
\hline $\mathrm{LvCn} 2$ & & & .75 & & & & & .80 & & & & & & \\
\hline LvCn5 & & & .79 & & & & & .82 & & & & .21 & & \\
\hline LvCn6 & & & .77 & & & & & .83 & & & & & & \\
\hline $\mathrm{LvCn} 7$ & & & .78 & & & & & .80 & & & & & & \\
\hline $\mathrm{LvCn} 8$ & & & .75 & & .20 & & & .79 & & & & & & \\
\hline CmEv5 & .74 & .21 & & & & & & & .74 & & & & & \\
\hline CmEv7 & .78 & & & & & & & & .78 & & & & & \\
\hline CmEv8 & .79 & .21 & & & & & & & .79 & .21 & & & .23 & \\
\hline CmEv9 & .74 & .23 & & & & & & & .73 & .21 & .21 & & .21 & \\
\hline CmEv10 & .78 & & & & & & & & .78 & & & & & \\
\hline LvWd2 & & & & & .21 & & .59 & & & & & & .74 & \\
\hline LvWd3 & .33 & & & .23 & & & .43 & & .27 & & .31 & & .54 & \\
\hline LvWd4 & & & & & & & .85 & & .22 & & & & .79 & \\
\hline LvWd5 & & & & & & & .83 & & .20 & .21 & & & .75 & \\
\hline LvWd7 & .31 & .31 & & .30 & & & .42 & & .25 & & .29 & & .58 & \\
\hline Inc2 & & & & .74 & & & & & & & .70 & & & \\
\hline Inc3 & & .22 & & .68 & & & & & & & .75 & & .21 & \\
\hline Inc4 & & & & .72 & & & & & .21 & .21 & .71 & & & \\
\hline Inc5 & & & & .72 & & & & & & & .74 & & & \\
\hline Inc8 & .35 & & & .58 & & & & & .23 & .27 & .61 & & .26 & \\
\hline Ath3 & & .62 & & .26 & & & & & .21 & .62 & .30 & & & \\
\hline Ath5 & & .72 & & & & & & & & .69 & .21 & & & \\
\hline Ath6 & .22 & .79 & & & & & & & .22 & .78 & & & & \\
\hline Ath8 & .21 & .75 & & & & & & & & .77 & & & .20 & \\
\hline Ath9 & & .75 & & .21 & & & & & & .82 & & & & \\
\hline E. value & 3.71 & 3.26 & 3.21 & 2.93 & 2.89 & 2.46 & 2.44 & 3.59 & 3.57 & 3.27 & 3.13 & 3.03 & 2.91 & 2.54 \\
\hline Alpha & .87 & .89 & .90 & .89 & .82 & .85 & .84 & .93 & .90 & .89 & .90 & .85 & .88 & .85 \\
\hline
\end{tabular}

Note. Acceptance (Acp), Rational parenting (RtioP), Loving control (LvCn), Compassion evoking (CmEv), Love withdrawal (LvWd),Inconsistent parenting (IncP), and Authoritarian parenting (AthP). 
Final Version of DPPS: For the present study, we used the abridged version of DPPS. The means of the five items in each factor elicited seven parental mean scores ranging from 0 to 3 that yielded a parenting profile for the father and the mother.

The psychological states scale (PSS): This scale was developed in Arabic by Hamuda and Imam (1996) to assess twenty-seven psychological states among adolescents and adults in Egypt. Five items pertaining to each state were designed, in each of which the subject is asked to endorse or reject a specific statement. A factor analysis and split-half reliability conducted on the scale, when applied to normal and clinical Arab groups in Egypt, indicated good internal-structural validity of the scale. Comparison of the two groups revealed significant differences between the normal and clinical participants in all subscales mentioned above (Hamuda and Imam, 1996). Since the present study is interested in a scale that assesses general mental health rather than differential diagnoses or psychotic disorders, and for economic reasons as well, we chose to use only three psychological states comprising five items each (fifteen items), covering three psychological disorders: anxiety disorder (I feel fear and anxiety for no apparent reason), depression (I feel sad most of the time), and conduct disorder (I always disobey orders and rules). The subjects were asked to rate their level of endorsement of each item on a four-point scale (from $3=$ always true to $0=$ not true).

This 15 items version of PSS was used by the primary author in many previous studies (Dwairy, 2007, 2009). To validate the scale on the present sample, a principal factor analysis was conducted on the fifteen PSS items with a varimax rotation and a 20 loading criterion. The analysis revealed two factors. The first explains $30.1 \%$ of the variance and was loaded by all ten items of anxiety and depression. Merging anxiety and depression in one factor was not surprising based on the high comorbidity between the two disorders (Hirschfeld, 2001). All five items of conduct disorder were loaded on the second factor, which explains $21.7 \%$ of the variance. The Cronbach's alpha coefficient of PSS in our sample was .88 and .81 for the internalized (anxiety and depression) and externalized (conduct disorder) problems, respectively, indicating good internal validity of the scale.

Based on this analysis, we derived three scores from the scale each ranges from 0 to 3 : internalized emotional disorders (the mean of ten anxiety and depression scores), externalized disorders (the mean of five conduct-disorder scores), and general psychological disorders (the mean of all fifteen scores), with a low score indicating better mental health.

\section{Results}

When the mean score for each factor was calculated, it was found that loving control is the most dominant parenting factor, with a mean of 2.35 and 2.41 for father and mother, respectively. The next two dominant factors were rational parenting and acceptance. The least used factor was compassion evoking (Table 2). Cross-gender differences will be discussed later.

Table 2. Parental factors means and standard deviation of fathers and mothers

\begin{tabular}{|c|c|c|c|c|c|c|}
\hline & & & All (975) & Boys & Girls & Significance \\
\hline \multirow[t]{14}{*}{ Father } & \multirow[t]{2}{*}{ Acp } & $\mathrm{M}$ & 1.95 & 1.95 & 1.97 & n.s. \\
\hline & & $\mathrm{Sd}$ & .71 & .71 & .71 & \\
\hline & \multirow[t]{2}{*}{ RtioP } & $\mathrm{M}$ & 2.05 & 2.06 & 2.04 & n.s. \\
\hline & & $\mathrm{Sd}$ & .67 & .67 & .66 & \\
\hline & \multirow[t]{2}{*}{$\mathrm{LvCn}$} & $\mathrm{M}$ & 2.35 & 2.37 & 2.32 & n.s. \\
\hline & & $\mathrm{Sd}$ & .66 & .60 & .72 & \\
\hline & \multirow[t]{2}{*}{$\mathrm{CmEv}$} & M & .58 & .67 & .49 & $\mathrm{P}<.000$ \\
\hline & & $\mathrm{Sd}$ & .63 & .64 & .59 & \\
\hline & \multirow[t]{2}{*}{ LvWd } & M & 1.16 & 1.23 & 1.09 & $\mathrm{P}<.009$ \\
\hline & & $\mathrm{Sd}$ & .77 & .77 & .78 & \\
\hline & \multirow[t]{2}{*}{ IncP } & M & 1.16 & 1.20 & 1.11 & $(\mathrm{P}<.082)$ \\
\hline & & $\mathrm{Sd}$ & .78 & .77 & .80 & \\
\hline & \multirow[t]{2}{*}{ AthP } & M & .92 & 1.00 & .83 & $\mathrm{P}<.001$ \\
\hline & & $\mathrm{Sd}$ & .79 & .79 & .77 & \\
\hline
\end{tabular}




\begin{tabular}{|c|c|c|c|c|c|c|}
\hline \multirow{20}{*}{ Mother } & \multirow[t]{2}{*}{ Acp } & $\mathrm{M}$ & .92 & 1.96 & 1.95 & n.s. \\
\hline & & $\mathrm{Sd}$ & .81 & .72 & .71 & \\
\hline & \multirow[t]{2}{*}{ RtioP } & $\mathrm{M}$ & 2.10 & 2.05 & 2.15 & $\mathrm{P}<.040$ \\
\hline & & $\mathrm{Sd}$ & .69 & .70 & .68 & \\
\hline & \multirow[t]{2}{*}{$\mathrm{LvCn}$} & $\mathrm{M}$ & 2.41 & 2.38 & 2.42 & n.s. \\
\hline & & $\mathrm{Sd}$ & .70 & .70 & .70 & \\
\hline & \multirow[t]{2}{*}{$\mathrm{CmEv}$} & $\mathrm{M}$ & .77 & .82 & .71 & $\mathrm{P}<.039$ \\
\hline & & $\mathrm{Sd}$ & .78 & .81 & .75 & \\
\hline & \multirow[t]{2}{*}{ LvWd } & $\mathrm{M}$ & 1.22 & 1.22 & 1.20 & n.s. \\
\hline & & $\mathrm{Sd}$ & .84 & .83 & .84 & \\
\hline & \multirow[t]{2}{*}{ IncP } & $\mathrm{M}$ & 1.08 & 1.10 & 1.04 & n.s. \\
\hline & & $\mathrm{Sd}$ & .80 & .79 & .80 & \\
\hline & \multirow[t]{2}{*}{ AthP } & $\mathrm{M}$ & .92 & .97 & .83 & $\mathrm{P}<.006$ \\
\hline & & $\mathrm{Sd}$ & .80 & .79 & .80 & \\
\hline & \multirow[t]{2}{*}{ Externalized } & $\mathrm{M}$ & .85 & .86 & .83 & n.s. \\
\hline & & $\mathrm{Sd}$ & .75 & .77 & .71 & \\
\hline & \multirow[t]{2}{*}{ Internalized } & $\mathrm{M}$ & 1.00 & .90 & 1.08 & $<.000$ \\
\hline & & $\mathrm{Sd}$ & .73 & .71 & .73 & \\
\hline & \multirow[t]{2}{*}{ Psy. Dis } & $\mathrm{M}$ & .95 & .89 & 1.00 & $<.008$ \\
\hline & & $\mathrm{Sd}$ & .66 & .65 & .66 & \\
\hline
\end{tabular}

Note. Acceptance (Acp), Rational parenting (RtioP), Loving control (LvCn), Compassion evoking (CmEv), Love withdrawal ( $\mathrm{LvWd})$, Inconsistent parenting ( $\mathrm{IncP})$, and Authoritarian parenting (AthP).

\subsection{Parenting Profiles}

To identify specific profiles of parents among our sample, a cluster analysis was conducted on the seven parental factors of father as well as of mother. The analysis identified two profiles among fathers and three profiles among mothers (Figure 1):

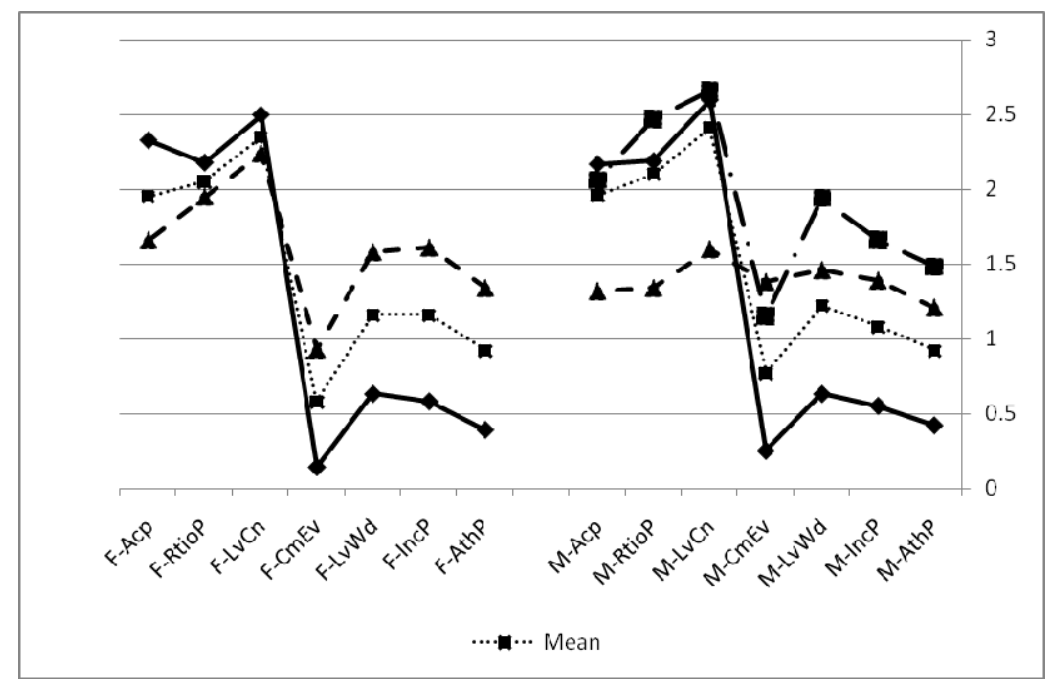

Figure 1. Fathers' (left) and mothers' (right) profiles

Note. Acceptance (Acp), Rational parenting (RtioP), Loving control ( $\mathrm{LvCn})$, Compassion evoking (CmEv), Love withdrawal ( $\mathrm{LvWd})$, Inconsistent parenting (IncP), and Authoritarian parenting (AthP). 
1) Low guidance-high control profile ( $L G-H C$ ): This profile, identified among 551 fathers and 204 mothers (Cluster1), is characterized by above-mean compassion evoking, love withdrawal, inconsistent parenting, and authoritarian parenting, and below-mean acceptance, rational parenting, and loving control parenting. Mothers' guidance in this profile (the left-hand side) is lower than fathers'.

2) High guidance-low control profile $(H G-L C)$ : This profile, identified among 421 fathers and 464 mothers (Cluster 2), is characterized by below-mean compassion evoking, love withdrawal, inconsistent parenting, and authoritarian parenting, and above-mean acceptance, rational parenting, and loving control parenting.

3) High guidance-high control profile (HG-HC): This profile, identified exclusively among mothers $(\mathrm{N}=307)($ Cluster 3$)$,is characterized by above-mean use of all parenting styles together.

\subsection{Parenting and Children's Psychological Disorders}

To study the association between parental factors and adolescents' psychological disorders, we calculated Pearson's correlation coefficients between each parental factor and adolescent psychological disorder and found that all the coefficients were significant. The sum squares of the coefficients of the fourteen correlations were .87, apparently suggesting that the explained variance of psychological disorders by the paternal and maternal parenting factors is $87 \%$. Because it is assumed that the parenting factors overlap and have much shared variance, this high percentage is illusive and misleading. Therefore, we conducted five linear regression analyses: two on parental factors and externalized and internalized psychological disorders that were found significant [adjusted $\mathrm{R}^{2}=.18, \mathrm{~F}(14,956)=15.79$, sig. $=000$; and adjusted $\mathrm{R}^{2}=.18, \mathrm{~F}(14,956)=16.07$, sig. $\left.=000\right]$ and three on parental factors and general psychological disorders of boys, girls, and all subjects together that were also significant [adjusted $\mathrm{R}^{2}=.19, \mathrm{~F}(14,486)=9.30$, sig. $=000$, adjusted $\mathrm{R}^{2}=.29, \mathrm{~F}(14,452)=13.80$, sig. $=000$; and adjusted $\mathrm{R}^{2}=.22$, $\mathrm{F}(14,956)=20.03$, sig. $=000$ respectively] (Table 3$)$.

Table 3 shows that some parental factors have no significant independent associations with adolescents' psychological disorders; they seem to operate in conjunction with other factors as components in a system. These are paternal acceptance, loving control, love withdrawal, and authoritarian control, and maternal love withdrawal and inconsistency.

Table 3. Beta values of regression analyses of parenting factors and externalized, internalized, and general psychological disorders of boys and girls

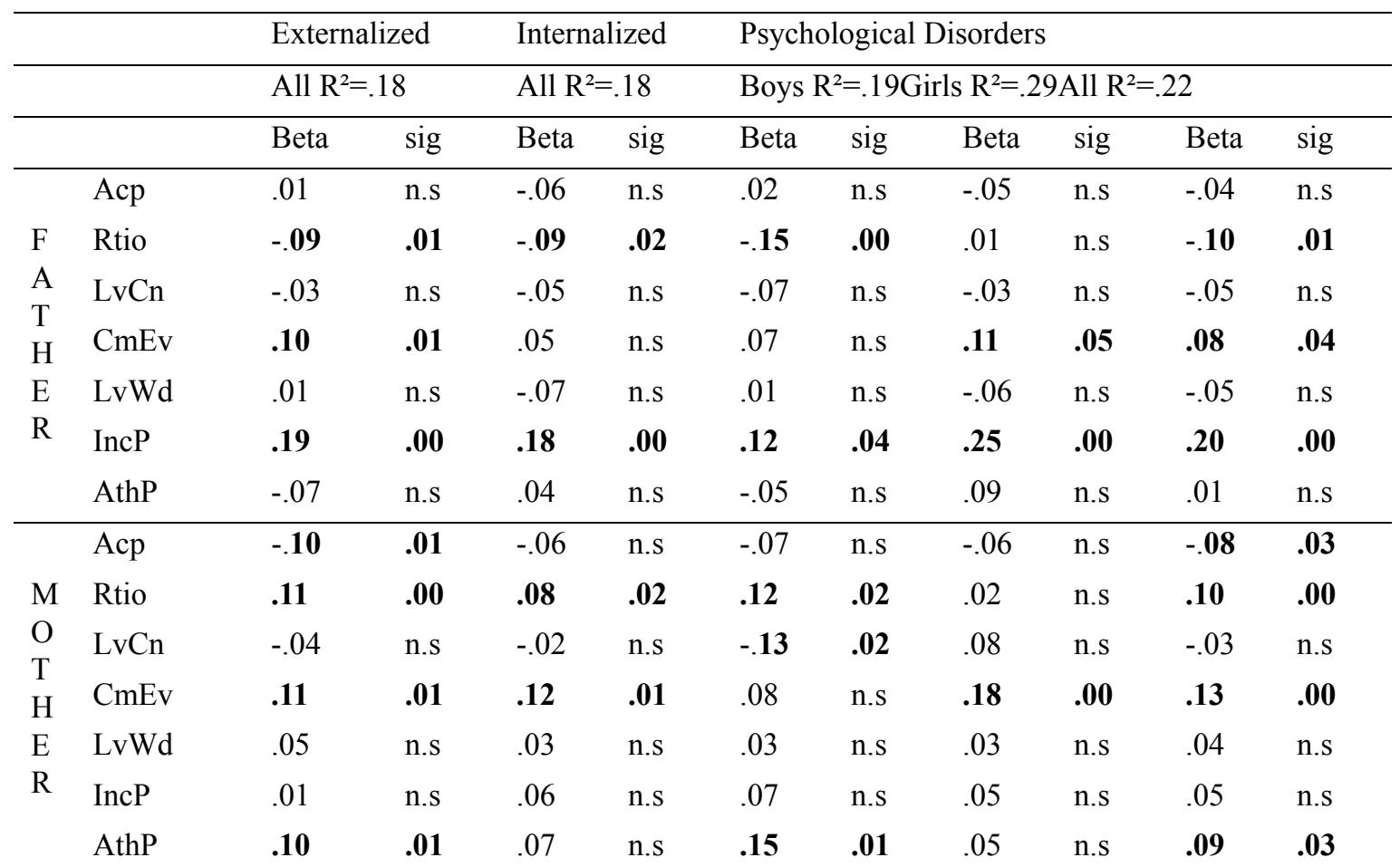

Note. Acceptance (Acp), Rational parenting (RtioP), Loving control ( $\mathrm{LvCn})$, Compassion evoking (CmEv), Love withdrawal (LvWd), Inconsistent parenting (IncP), and Authoritarian parenting (AthP). 
To study the differences between parents with different parenting profiles in terms of adolescents' psychological disorders, an ANOVA was conducted and found that the mean psychological disorders of adolescents of fathers $(\mathrm{M}=.71)$ and mothers $(\mathrm{M}=.71)$ with HG-LC profiles was significantly lower than the other profiles: $L G-H C$, and $H G-H C[\mathrm{~F}(1,964)=100.18, \alpha<.0001 ; \mathrm{F}(1,964)=63.11, \alpha<.0001$ respectively] (Table 4). Similar significant differences in externalized and internalized disorders were found. No significant differences in psychological disorders between LG-HC and HG-HC of mothers were found.

To test the combined effect of different paternal and maternal profiles on the psychological disorders, a GLM analysis of variance was conducted. It elicited a significant difference between the two paternal profiles $\left[\mathrm{F}(959,1)=25.39, \alpha<.0001\right.$, Partial $\left.\mathrm{Eta}^{2}=.03\right]$ and among the three maternal profiles $[\mathrm{F}(959,2)=24.32, \alpha<.0001$, Partial $\left.\mathrm{Eta}^{2}=.05\right]$. No significant interaction effect was found (Table 4).

Table 4. Means of psychological disorders according to fathers and mothers clusters

\begin{tabular}{llllll}
\hline & & & & \\
\cline { 3 - 5 } & & & CATHER & & \\
\hline \multirow{3}{*}{$\mathrm{M}$} & Clst\#1LG-HC & $\mathrm{M}$ & 1.26 & .89 & 1.19 \\
$\mathrm{O}$ & & $\mathrm{SD}$ & .71 & .55 & .69 \\
$\mathrm{~T}$ & $\mathrm{~N}$ & 165 & 36 & 201 \\
\cline { 3 - 6 } $\mathrm{H}$ & Clst\#2HG-LC & $\mathrm{M}$ & .88 & .64 & .71 \\
$\mathrm{E}$ & & $\mathrm{SD}$ & .53 & .51 & .53 \\
$\mathrm{R}$ & $\mathrm{N}$ & 138 & 313 & 451 \\
\cline { 3 - 6 } & Clst\#3HG-HC & $\mathrm{M}$ & 1.13 & 1.00 & 1.15 \\
& & $\mathrm{SD}$ & .71 & .74 & .72 \\
& & $\mathrm{~N}$ & 245 & 62 & 307 \\
\hline & Total & $\mathrm{M}$ & 1.13 & .71 & \\
& & $\mathrm{SD}$ & .68 & .57 & \\
& & $\mathrm{~N}$ & 548 & 411 & \\
\hline
\end{tabular}

Note. Low Guidance (LG), High Guidance (HG, Low Control (LC), and High Control (HC).

The results show that the psychological states of adolescents were worst when both father and mother adopted an LG-HC pattern $(\mathrm{M}=1.26)$ and best when both parents adopted an HG-LC pattern $(\mathrm{M}=.64)$.

The regression analyses indicate that the associations between parenting and adolescents' psychological disorders depend on the kind of disorder (externalize/internalized), the adolescents' sex (boys/girls), and the parents' sex (fathers/mothers) (Table 3).

\subsection{Externalized versus Internalized Disorders}

Both externalized and internalized disorders were higher when parents had an LG-HC profile and when mothers had an HG-HC profile (Table 4).The explained variance of the externalized and internalized psychological disorders by parental factors was similar (18\%) (Table 3). Both types of disorders, externalized and internalized, were associated with lack of paternal rational parenting and inconsistency and with maternal rational parenting and compassion evoking. In addition to these shared factors, externalized disorders were associated with paternal compassion evoking and maternal authoritarian parenting.

\subsection{Cross-Gender Differences and Associations of Parents and Adolescents}

A one-way variance analysis with Bonferroni correction was conducted to test for differences between boys and girls. The results show that fathers apply more control to sons than they do to daughters through compassion evoking, love withdrawal, inconsistent parenting, and authoritarian parenting. Mothers, in turn, apply more control to their sons through compassion evoking and authoritarian parenting (Table 2); in addition, they use more rational parenting with daughters than with sons. To test for cross-gender associations in terms of profiles, a Chi square analysis was conducted, showing that the LG-HC paternal profile was applied more to boys than to girls and the HG-LC paternal profile was applied more to girls $\left[\mathrm{Chi}^{2}(1)=6.64, \mathrm{p}<.006, \mathrm{Eta}^{2}=.084\right]$. The maternal 
profiles were applied to boys and girls equally.

Female adolescents reported stronger symptoms of internalized emotional disorders such as anxiety and depression than boys. No differences were found between boys and girls in conduct-disorder symptoms (Table 3). The explained variance of girls' psychological disorders by paternal and maternal factors was higher than that of boys ( $29 \%$ vs. $18 \%$ ). Boys' psychological disorders were associated with lack of fathers' rational parenting and inconsistent parenting and with mothers' rational parenting and authoritarian parenting and lack of loving control parenting. Girls' psychological disorders were associated with fathers' compassion evoking and inconsistent parenting, and with mothers' compassion evoking (Table 3).

Associations of psychological disorders with acceptance and authoritarian parenting were significant among mothers but insignificant among fathers. Associations with inconsistency were significant among fathers but insignificant among mothers. Interestingly, rational parenting played opposite roles in adolescents' psychological disorders when applied by fathers and by mothers: fathers' rational parenting was associated with a better psychological state but mothers' rational parenting was associated with more severe psychological disorders. Both paternal and maternal compassion evoking was associated with psychological disorders. Paternal and maternal love withdrawal was not associated with psychological disorders among boys or girls. Loving control was not associated with psychological disorders with the exception of maternal loving control, which was associated exclusively with boys' psychological disorders.

\section{Discussion}

The purpose of our research was to study seven parental factors together to identify parental profiles and link them to adolescents' psychological states. The seven factors were acceptance, rational parenting, loving-control parenting, compassion evoking, love withdrawal, inconsistent parenting, and authoritarian parenting.

According to the adolescents' reports the most common parental practices among fathers and mothers were: loving control, rational parenting, and acceptance, indicating that parents apply higher Guidance than Control practices. Thus, the multi-factorial measures of parenting enabled us to know how parents in a collective and authoritarian society, such as the Arab society (Dwairy, 2006), apply their guidance or control over their children. A cross-cultural research in the future will be interesting in order to study qualitative differences in control practices of parents.

Although all parental factors have significant correlation coefficients with psychological disorders, when all factors are analyzed together in one regression they explain only $22 \%$ of the variance of psychological disorders (Table 3). Furthermore, paternal acceptance, loving control, love withdrawal, and authoritarian parenting, and maternal love withdrawal and inconsistency were not associated, each in isolation, with externalized or internalized disorders among boys or girls. This indicates that the parenting factors have a high overlap and work together as one integral system of intervention in response to adolescents' behavior. This finding justifies our approach of studying parental profiles rather than parental factors.

Cluster analysis helped us to identified two paternal and three maternal profiles that were associated with different levels of psychological disorders (Table 4). The profiles that we found vary according to two groups of parenting factors: (a) guiding parenting that includes acceptance, loving control, and rational control, which were the dominant factors among both fathers and mothers (Table 3) and were associated with better psychological states (Table 3); and (b) controlling parenting that includes compassion evoking, love withdrawal, inconsistent parenting, and authoritarian parenting, which were less dominant and were associated with psychological disorders(Figure 1).

The parenting profile of $43 \%$ of fathers and $48 \%$ of mothers was the high guidance-low control profile (HG-LC), which was associated with better psychological adjustment (Table 4). The remaining $57 \%$ of fathers and $21 \%$ of mothers exhibited the low guidance-high control profile (LG-HC), which was associated with psychological disorders. The remaining $31 \%$ of mothers displayed the high guidance-high control profile (HG-HC), which was also associated with psychological disorders. This maternal profile is a confusing and inconsistent one that combines high control and high guidance; it reflects desperate and helpless mothers who overuse every possible tool to gain control over their children. This association, of course, may be reciprocal: a maternal HG-HC profile hurts the adolescent's psychological state or more severe psychological disorders render the mother helpless and confused, inducing her to use all possible tools.

This combination of all parenting factors among 307 mothers may explain the positive association $(\beta=.10)$ found exclusively between maternal rational control and psychological disorders, the opposite of the negative association $(\beta=-.10)$ found among fathers (Table 3$)$. This highlights the importance of studying parenting as a 
complex of profiles because no parenting factor works on its own, rather always working within a complex of factors. Therefore, when some mothers applied rational control together with other controlling factors, it established an association with psychological disorders. In addition, this reverse effect of rational control presented exclusively with boys (fathers' $\beta=-15$; mothers' $\beta=.12$ ) and not with girls. This unexpected result may reflect the differences between male roles (fathers/sons) and female roles (mothers/daughters) in patriarchal Arab families. Since fathers are considered the ultimate rule-making authorities, when they explain to sons what will happen as a consequence of a given behavior and the explanation is consistent, they may help sons to adjust better to the environment. Mothers, in contrast, are not considered authorities; instead, they are expected to be accepting and warm and serve as facilitators between children and fathers. Therefore, when a mother becomes authoritarian, making rules and explain consequences, although rationally, she is not taken seriously and may tumble into a state of helplessness. A common and well known practice among Arab mothers is to attempt to gain control over sons by threatening, "Wait "till your father comes home!" Often when the father does come home, the mother does not deliver the report or he fails to act as she expects. This maternal verbal style, although redolent of rational rules, indicates helplessness and loss of control; therefore, it is associated with boys' psychological disorders. This familial system may also explain why mothers' authoritarian parenting is exclusively associated with boys' psychological disorders $(\beta=.15)$ while the same parenting practice applied by fathers is not associated with psychological disorders among either boys or girls. Maternal authority is seemingly considered inconsistent with mothers' role and an unaccepted extension of their limited duties in Arab families; therefore, an authoritarian style seems inefficient when applied by the maternal parent. Alternatively, Arab mothers may become authoritarian when they lose control over male children, hence the association between authoritarian parenting by mothers and boys' psychological disorders.

As for cross-gender differences, both fathers and mothers tend to apply more control to boys than on girls (Table 3), a finding consistent with former studies in various Arab countries (Dwairy, Achoui, Abouserie, Farah, Ghazal, Fayad, \& Khan, 2006). This higher level of control over boys in a patriarchic society (Dwairy, 2006) is explained in view of the assumption that boys in this system dare more to challenge their parents, necessitating bolder control over them.

Comparing boys and girls in terms of parenting factors and psychological disorders, we found that the explained variance of psychological disorders by parental variables was higher among girls (29\%) than among boys (19\%), indicating that parents' attitudes and behaviors influence girls more than boys. This difference may be attributed to the fact that Arab girls spend more time at home than boys while boys are exposed more to social influences outside their homes (Dwairy, 2006). In addition, although inconsistent paternal parenting was the factor of greatest influence on both sexes, girls were influenced badly $(\beta=.25)$ by paternal inconsistency but not at all by maternal inconsistency. Paternal inconsistency, then, appears to have a special meaning and influence in Arab families, especially on girls. It may indicate that the family rules are vague, that a father can burst out unexpectedly at any time, and that this is a serious threat. Paternal and maternal compassion evoking styles affected girls only, indicating that girls are more sensitive than boys to parents' feelings. These cross-gender differences are consistent with former results that indicated such differences (Dwairy, 2010; Dwairy, Achoui, 2010; Rohner, personal communication, August 13, 2010; Tulviste \& Rohner, 2010).

Generally speaking, our results indicate that good parenting in Arab society is attained when fathers apply consistent and rational parenting and avoid compassion evoking, and when mothers apply acceptance and avoid confused rational, compassion evoking, and authoritarian parenting. Psychological disorders were lowest $(\mathrm{M}=.64)$ when both father and mother adopted an HG-LC pattern and highest $(\mathrm{M}=1.26)$ when both adopted an LG-HC pattern (Table 4).

The associations between parental factors and externalized or internalized disorders appear to be similar: Explaining similar variance of disorders (18\%) and both disorders were associated with LG-HC profile (Table 4) and with lack of paternal rational parenting and with paternal inconsistency, and associated with maternal rational and compassion evoking parenting (Table 3). The only difference was the association of paternal Compassion Evoking, maternal authoritarian parenting, and lack of maternal acceptance with externalized disorders. The difference may indicate that when adolescents evince conduct problems, fathers try to control them by evoking compassion and mothers try to do so with authoritarian parenting, in addition to the other factors. Alternatively, it may indicate a relation between conduct disorders and authoritarian control by mothers and compassion-evoking by non-authoritarian fathers. Generally speaking, the similarity in the associations between parenting profiles and externalized and internalized disorders may indicate that the type of disorder manifested by the child is related less to parenting than to other factors, such as genetic or social ones.

The strength of our research is that it captures a variety of parenting factors and differentiates among styles of 
parental control, enhancing our understanding of the parenting system, and was applied across a large sample from three Arab societies. To the best of our knowledge, this is the first research that studied parenting in terms of profiles and detected specific profiles and their associations with adolescents' psychological disorders. The weakness of our research is that it is based exclusively on adolescents' self-reportage. To validate our findings, we have begun to study parenting profiles via parents' self-reportage and to collect data from a clinical sample. Our research must be applied to other Western and non-Western samples, of course.

\section{References}

Barber, B., Olsen, J., \& Shagle, S. (1994). Associations between parental psychological and behavioural control and youth internalizing and externalizing behaviours. Child Development, 65, 1120-1136. http://dx.doi.org/10.2307/1131309

Baumrind, D. (1966). Effects of authoritative parental control on child behavior. Child Development, 37, 887-907. http://dx.doi.org/10.2307/1126611

Baldwin, A. L., Baldwin, C., \& Cole, R. E. (1990). Stress-resistant families and stress-resistant children. In J. Rolf, A. Masten, D. Chicchetti, K. Nuechterlein, \& S. Weintraub (Eds.), Risk and protective factors in the development of psychopathology (pp. 257-280). Cambridge, UK: Cambridge University Press. http://dx.doi.org/10.1017/CBO9780511752872.016

Baumrind, D. (1991). The influence of parenting style on adolescent competence and substance use. Journal of Early Adolescence, 11, 56-95. http://dx.doi.org/10.1177/0272431691111004

Baumrind, D. (2005). Patterns of parental authority and adolescent autonomy. New Directions for Child and Adolescent Development (Wiley Periodicals, Inc.), 108, 61-69. http://dx.doi.org/10.1002/cd.128

Buri, J. R., Louiselle, P. A., Misukanis, T. M., \& Mueller, R. A. (1988). Effects of parental authoritarianism and authoritativeness on self-esteem. Personality and Social Psychology Bulletin, 14(2), 271-282. http://dx.doi.org/10.1177/0146167288142006

Dadds, M. R. (1995). Families, children, and the development of dysfunction. New York: Sage.

Dwairy, M. (2006). Counseling and Psychotherapy with Arabs and Muslims: A Culturally Sensitive Approach. New York: Teachers College Press, Columbia University.

Dwairy, M. (Nov. 2006). Causality and the Phenomenon of Contradictory Outcomes in Research. Journal of Chinese Clinical Medicine, 5, 272-282 (a Chinese reviewed journal). Retrieved from http://www.cjmed.net/newsContent.aspx?id=67

Dwairy, M. (2007). Parental inconsistency versus parental authoritarianism: Association with symptoms of psychological disorders. Journal of Youth and Adolescence.

Dwairy, M. (2009). Parenting and Adolescents' Psychological Adjustment: Towards a Systemic Approach in Parenting Research. The Open Family Studies Journal, 2, 73-81. http://dx.doi.org/10.2174/1874922400902010066

Dwairy, M. (2010). Parental acceptance-rejection: A fourth cross-cultural research on parenting, culture, and psychological adjustment of children. Journal of Child and Family Studies, 19(1), 30-35. http://dx.doi.org/10.1007/s10826-009-9338-y

Dwairy, M., \& Achoui, M. (2010). Parental control: A second cross-cultural research study on parenting, culture, and psychological adjustment of children. Journal of Child and Family Studies, 19(1), 16-22. http://dx.doi.org/10.1007/s10826-009-9334-2

Dwairy, M., Achoui, M., Abouserie, R., Farah, A., Ghazal, I, Fayad, M., \& Khan, H. (2006). Parenting styles in Arab societies: A first cross-regional research study. Journal of Cross-Cultural Psychology, 37(3), 230-247. http://dx.doi.org/10.1177/0022022106286922

Dwairy, M., Achoui, M., Abouserie, R., \& Farah A. (2006). Parenting styles, individuation, and mental health of Arab adolescents: A third cross-regional research study. Journal of Cross-Cultural Psychology, 37(3), 262-272. http://dx.doi.org/10.1177/0022022106286924

Dwairy, M., \& Menshar, K. E. (2006). Parenting style, individuation, and mental health of adolescents in Egypt. Journal of Adolescence, 29, 103-117. http://dx.doi.org/10.1016/j.adolescence.2005.03.002

Hamuda, M. A., \& Imam, I. A. (1996). The Psychological State Scale for adolescents and adults. Cairo, Egypt: Dar El Fekr El Arabi (in Arabic). 
Hirschfeld, R. M. A. (2001). The Comorbidity of Major Depression and Anxiety Disorders: Recognition and Management in Primary Care. J of Clinical Psychiatry, 3(6), 244-254.

Hersov, L. (1960). Persistent non-attendance at school. Journal of Child Psychology and Psychiatry, 1, 130-136. http://dx.doi.org/10.1111/j.1469-7610.1960.tb01987.x

Hofstede, G. (2001). Culture's consequences: Comparing values, behaviors, institutions and organizations across nations. Beverly Hills, CA: Sage Publications.

Kim, E., Cain, K., \& McCubbin, M. (2006). Maternal and paternal parenting, acculturation, and young adolescents' psychological adjustment in Korean American families. Journal of Child and Adolescent Psychiatric Nursing, 19(3), 112-129. http://dx.doi.org/10.1111/j.1744-6171.2006.00059.x

Lamborn, S. D., Mants, N. S., Steinberg, L., \& Dornbusch, S. M. (1991). Patterns of competence and adjustment among adolescents from authoritative, authoritarian, indulgent, and neglectful families. Child Development, 62, 1049-106. http://dx.doi.org/10.2307/1131151

Maccoby, E. E., \& Martin, J. A. (1983). Socialization in the context of the family: Parent child interaction. In P. H. Mussen, \& E. M. Hetherington (Eds.), Handbook of child psychology (Vol. 4, pp. 1-102). New York: Wiley.

McLeod, B. D., Wood, J. J., \& Weisz, J. R., (2007). Examining the association between parenting and childhood anxiety: A meta-analysis. Clinical Psychology Review, 27, 155-172. http://dx.doi.org/10.1016/j.cpr.2006.09.002

McLeod, B. D., Weisz, J. R., \& Wood, J. J. (2007). Examining the association between parenting and childhood depression: A meta-analysis. Clinical Psychology Review, 27(8), 986-1003. http://dx.doi.org/10.1016/j.cpr.2007.03.001

Patterson, G. R. (1982). A social learning approach: Coercive family process. Eugene, OR: Castalia.

Reitman, D., Rhode, P. C., Hupp, S. D. A., \& Altobello, C. (2002). Development and validation of the parental authority questionnaire - revised. Journal of Psychopathology and Behavioral Assessment, 24(2), 119-127. http://dx.doi.org/10.1023/A:1015344909518

Rohner, R. P. (1986). The warmth dimension: Foundations of parental acceptance-rejection theory. Beverly Hills, CA: Sage.

Rohner, R. P. (1999). Acceptance and rejection. In D. Levinson, J. Ponzetti, \& P. Jorgensen (Eds.), Encyclopedia of human emotions (Vol. 1, pp. 6-14). New York: Macmillan.

Rohner, R. P., \& Khaleque, A. (2003). Reliability and validity of parental control scale: A meta-analysis of cross-cultural and intercultural studies. Journal of Cross-Cultural Psychology, 34(6), 643-649. http://dx.doi.org/10.1177/0022022103255650

Rohner, R. P., \& Khaleque, A. (Eds.). (2005). Handbook for the study of parental acceptance and rejection (4th ed.). Storrs, CT: Rohner Research Publications.

Rohner, R. P., Khaleque, A., \& Cournoyer, D. E. (2005). Parental acceptance-rejection theory, methods, evidence, and implications. Retrieved January 27, 2005, from http://vm.uconn.edu/-rohner

Rothbaum, F., \& Weisz, J. R. (1994). Parental caregiving and child externalizing behaviour in a nonclinical sample: A meta-analysis. Psychological Bulletin, 116, 55-74. http://dx.doi.org/10.1037/0033-2909.116.1.55

Schaefer, E. S. (1965). Children's reports of parental behavior: An inventory. Child Development, 36, 413-424. http://dx.doi.org/10.2307/1126465

Soenens, B. (September, 2007). "I will love you if you do as I say": How psychological controlling parenting undermines parent-child acceptance. International Society for Interpersonal acceptance and Rejection (Newsletter), 1(3), 1-3.

Steinberg, L., Mounts, N., Lamborn, S., \& Dornbusch, S. (1991). Authoritative parenting and adolescent adjustment across varied ecological niches. Journal of Research on Adolescence, 1, 19-36.

Steinberg, L., Lamborn, S., Dornbusch, S., \& Darling, N. (1992a). Impact of parenting practices on adolescent achievement: Authoritative parenting, school involvement, and encouragement to succeed. Child Development, 63, 1266-1281. http://dx.doi.org/10.2307/1131532

Steinberg, L., Dornbusch, S., \& Brown, B. B. (1992b). Ethnic differences in adolescent achievement: An ecological perspective. American Psychologist, 47, 723-729. http://dx.doi.org/10.1037/0003-066X.47.6.723 
Tulviste, T., \& Rohner, R. P. (2010). Relationships between perceived teachers' and parental behavior and adolescent outcomes in Estonia. Cross-Cultural Research, 44(3) 222-238. http://dx.doi.org/10.1177/1069397110366797

Wenar, C. (1994). Developmental psychopathology: From infancy through adolescence. New York: McGraw Hill.

Winnicott, D. W. (1958). Mind and its relation to the psyche-soma. In Collected papers, through pediatrics to psychoanalysis (pp. 243-54). London: Tavistock Publications.

\section{Copyrights}

Copyright for this article is retained by the author(s), with first publication rights granted to the journal.

This is an open-access article distributed under the terms and conditions of the Creative Commons Attribution license (http://creativecommons.org/licenses/by/3.0/). 